$(\mathrm{n}=1925)$. Mean levels of aggression, anger and fear were analysed by gender and alcohol involvement. Multinomial models estimated associations of drinking patterns with aggression to and from the respondent.

Results The response rate was 49\%. Men and women reported similar prevalence of victimisation and perpetration of aggression $(11 \%-15 \%)$. Alcohol was involved in more than a quarter of incidents, and reported more often by women than men, particularly male-only drinking when the respondent was victimised. Women reported more severity, anger and fear accompanying victimisation than men, and these scores differed significantly by involvement of alcohol. Heavy episodic drinking by respondents was associated with a threefold increase in victimisation involving alcohol, and doubling of perpetration of aggression involving alcohol.

Conclusion In a cross-section of households, "counts" of aggressive acts do not reflect the reality of gender differences. The frequency of heavy drinking episodes is associated with the occurrence of aggression involving alcohol within relationships, and the involvement of alcohol in an incident of aggression is associated with increased severity, fear and anger particularly for women.

\section{P1-415 SOCIOECONOMIC STATUS AND SURGICAL OUTCOME AFTER HYSTERECTOMY}

doi:10.1136/jech.2011.142976g.5

\begin{abstract}
${ }^{1,2} \mathrm{~S}$ Daugbjerg, ${ }^{*}{ }^{3} \mathrm{G}$ Cesaroni, ${ }^{2} \mathrm{~B}$ Ottesen, ${ }^{4} \mathrm{~F}$ Diderichsen, ${ }^{1} \mathrm{M}$ Osler. ${ }^{1}$ Research Centre for Prevention and Health, Glostrup University Hospital, Glostrup, Capital Region of Denmark, Denmark; ${ }^{2}$ Department of Gynaecology, Juliane Marie Centre, Rigshospitalet, Copenhagen, Denmark; ${ }^{3}$ Department of Epidemiology, Local Health Authority Rome E, Rome, Italy; ${ }^{4}$ Department of Social Medicine, Institute of Public Health, University of Copenhagen, Copenhagen, Denmark
\end{abstract}

Objective To examine the association between socioeconomic status (SES) and eight selected surgical outcomes after hysterectomy and asses the role of lifestyle, co-morbidity and clinical conditions on the relationship.

Methods All 22150 women registered with a benign elective hysterectomy code in the national Danish Hysterectomy Database (DHD) from 2004 to 2008 were included in the study. Data from DHD were linked to several central registers providing information on education, employment, income, lifestyle factors, co-morbidities and surgical outcome. Data were analysed using multilevel logistic regression models.

Results Overall $17 \%$ of the women experienced a clinical complication in relation to hysterectomy. Four per cent were re-operated, $6 \%$ readmitted and $6 \%$ experienced prolonged hospitalisation $\geq 5$ days. Women with short education had a higher risk of complications than women with higher education after adjusting for patient characteristics ( $O R=1.15,95 \%$ CI 1.02 to 1.31$)$. They also had a higher risk of peroperative bleeding after adjusting for lifestyle factors and comorbidity ( $\mathrm{OR}=1.60$, CI 1.15 to 2.22). Furthermore, a higher risk of infection and readmission was observed however, these relations seemed fully explained by lifestyle factors and co-morbidity. Women out of employment had a higher risk of infection, organ lesion, prolonged hospitalisation and readmission than women in employment. We found no association between income and surgical outcome after hysterectomy.

Conclusion This study suggests that women with low SES have a significant worse surgical outcome after hysterectomy than women with high SES when differences in lifestyle factors and co-morbidity are taking into account.

\section{P1-416 SECULAR TREND OF OVERWEIGHT AND OBESITY IN ADOLESCENTS OF HIGH SOCIOECONOMIC LEVEL FROM A DEVELOPED CITY IN THE SOUTHEAST OF BRAZIL}

doi:10.1136/jech.2011.142976g.6

${ }^{1} \mathrm{~S} D$ Castilho, ${ }^{1} \mathrm{C}$ A Bento, ${ }^{1} \mathrm{C}$ D Pinheiro, ${ }^{1} \mathrm{M}$ Cocetti, ${ }^{2} \mathrm{~A}$ de Azevedo Barros. ${ }^{*}{ }^{1}$ Faculty of Medicine-Puccamp, Campinas, São Paulo, Brazil; ${ }^{2}$ State University of Campinas Medical School, Campinas, São Paulo, Brazil

Introduction Although already of high prevalence, overweight and obesity are still increasing in many parts of the world. The objective was to evaluate the secular trend of overweight and obesity in adolescents of high socioeconomic level over a decade in a developed city of Brazil.

Method Two cross-sectional studies included 2825 students (1348 evaluated in 2001 and 1477 evaluated in 2010) of both genders and ages 7 to 18 years, from private schools in Campinas, SP, Brazil. The schools were randomly chosen. The first sample included 663 boys and 685 girls and the second included 709 boys and 763 girls. The BMI/age cut-off points of the Who Growth Standards 2007 were considered in the nutritional diagnosis: overweight $>+1 \mathrm{SD}$ and obesity $>+2$ SD. This study was approved by the Research Ethics Committee of PUC-Campinas (protocol no. 693/09).

Results The percentage of overweight adolescents (23\%) remained stable during this period. Obesity increased from 10\% (95\% CI 8.4 to $11.6)$ in 2001 to $15 \%$ (95\% CI 13.2 to 16.8 ) in 2010. Overweight and obesity were greater in boys than girls in both samples. Overweight and obesity were respectively $25 \%$ and $15 \%$ (95\% CI 12.3 to 17.7 ) in $2001,23 \%$ and $19 \%$ (95\% CI 16.1 to 21.9 ) in 2010 for boys, and $22 \%$ and $6 \%(95 \%$ CI 5.1 to 6.9$)$ in 2001 and $22 \%$ and $10 \%$ (95\% CI 7.9 to 12.1) in 2010 for girls.

Conclusion These data show that obesity are increasing and point to the need for immediate interventions in order to prevent this trend.

\section{P1-417 DOES LIFE-COURSE SOCIOECONOMIC POSITION EXPLAIN COLOUR/RACE INEQUALITIES IN THE PREVALENCE OF SELF- REPORTED UTERINE LEIOMYOMAS? EVIDENCE FROM THE PRÓ-SAÚDE STUDY, BRAZIL}

doi:10.1136/jech.2011.142976g.7

Karine de Lima Sírio Boclin, ${ }^{*}$ E Faerstein. Universidade do Estado do Rio de Janerio, Rio de Janeiro, RJ, Brazil

Introduction USA studies showed that uterine leiomyomas (UL) occur more frequently among black women, but the nature of this association remains largely unexplained. Because black women are disproportionately disadvantaged in social hierarchies, such racial inequality might be explained by life-course socioeconomic adversity. Aim To investigate whether life-course socioeconomic position (SEP) - during childhood, early adulthood, or lifelong-is a mediator of associations between colour/race and UL among Brazilian women. Methods We analysed data from self-administered questionnaires completed by 1534 female civil servants at a Rio de Janeiro university during the baseline data collection of the Pró-Saúde Study. Three study outcomes were explored: self-reported medical diagnosis of UL; UL with symptoms prior to diagnosis; and hysterectomy due to UL. The childhood SEP was assessed by parental education and the early adulthood SEP measured by participants' education; the cumulative SEP measures resulted from a combination of the previous information. We estimated ORs and 95\% CIs by logistic regression models.

Results Compared to whites, black and brown (mixed race) women presented risks respectively $1.6(95 \%$ CI 1.2 to 2.1$)$ and 1.4 (95\% CI 0.8 to 2.5$)$ higher of UL. This estimate was higher for those submitted to hysterectomy due to UL (blacks-OR: 2.6 to $1.7 ; 4.0$ 
and brown-OR: 1.1 to 0.9 ; 1.5). These estimates were not significantly altered in models including variables related to life-course SEP. Conclusion In this Brazilian population, UL risk increased with the darkening of skin colour, and the life-course SEP did not mediate this association.

\section{P1-418 PREVALENCE OF DENTAL PAIN AND ASSOCIATED FACTORS AT 5 YEARS OLD: FINDINGS FROM A BRAZILIAN BIRTH COHORT}

doi:10.1136/jech.2011.142976g.8

\begin{abstract}
${ }^{1} \mathrm{~F}$ Demarco, ${ }^{* 1} \mathrm{G}$ Boeira, ${ }^{1} \mathrm{M}$ Correa, ${ }^{2} \mathrm{~K}$ Peres, ${ }^{2} \mathrm{M}$ Peres, ${ }^{1} \mathrm{I}$ Santos, ${ }^{1} \mathrm{~A}$ Matijasevich, ${ }^{1}$ A Barros. ${ }^{1}$ Federal University of Pelotas, Pelotas, Rio Grande do Sul, Brazil, ${ }^{2}$ Federal University of Santa Catarina, Florianopolis, Santa Catarina, Brazil
\end{abstract}

Introduction Despite dental pain being an important public health issue, very few studies have investigated its occurrence in preschool children using a life course approach. The objective of this study was to describe the prevalence of dental pain in preschool children and its association with life course characteristics.

Methods This study was nested in a population-based birth cohort from Pelotas, Brazil, started in 2004. A sample of 1129 children aged 5 years old underwent dental examination and their mothers were interviewed. Exploratory variables included sociodemographic factors, maternal oral health status and associated behaviours, and children's primary dental caries. Data were analysed using multivariable Poisson regression.

Results Toothache was present in $16.5 \%$ of the population in the 6 months prior to interview. Adjusted analyses showed that darkskinned children [Prevalence ratio (PR)=1.6 (95\% CI 1.1 to 2.4)], from low economic level [PR 1.9 (1.2 to 3.0)], whose mothers had $<4$ years of study [PR 1.9 (1.0 to 3.6)], and whose mothers with $<10$ teeth in one arch at least [PR 1.66 (1.09 to 2.53)], and those with high caries prevalence at age 5 years [PR 4.8 (3.3 to 7.1)] were associated with dental pain.

Conclusions Low family income and lack of children's schooling are the main early life risk factors for dental pain in preschool children. Poor maternal and child dental status are associated with dental pain. The socioeconomic and family context in which dental pain occurs should be taken into account when dental pain preventive measures are implemented.

\section{P1-419 HEALTH PROMOTING SCHOOL INITIATIVE IN ASHRAM SCHOOLS OF WARDHA DISTRICT: AN EVALUATION}

doi:10.1136/jech.2011.142976g.9

${ }^{1} \mathrm{~A}$ Dongre, ${ }^{*} \mathrm{P}$ Deshmukh, ${ }^{2} \mathrm{~B}$ Garg. ${ }^{1}$ Department of Community Medicine, Sri Manakula Vinayagar Medical College, Pondicherry, India; ${ }^{2}$ Dr Sushila Nayar School of Public Health, Mahatma Gandhi Institute of Medical Sciences, Sewagram, India

Objective To study the effect of health promoting school-based intervention for disadvantaged children in the residential Ashram Schools of rural Wardha district of central India.

Material and Methods At baseline, 1287 children in 10 Ashram schools were examined using locally adopted Global School-based Student Health Survey questionnaire. Ashram (residential) schools are residential schools providing lodging and boarding, uniforms, books and notebooks and educational equipments to its poor inmates. It covered information on personal hygiene, physical status, nutrition, environment, substance abuse, risk behaviour, life skills and others. Haemoglobin examination of all children was done by using Haemoglobin colour scale. Body Mass Index (BMI) and Physical activity score for each child was calculated. Intervention was carried out through trained school health committee members. After 1 year, 1226 children were examined as end line assessment by using the same questionnaire. The data were entered and analysed using Epi info software.

Results Overall, there was significant improvement in the status personal hygiene and reduction in related morbidities among school children. Noteworthy, percentage of current tobacco consuming children declined significantly from 506 (39.3\%) to 210 (17.1\%). The mean haemoglobin of the children increased from $10.7 \mathrm{~g} / \mathrm{dl}$ to $11.4 \mathrm{~g} /$ dl. Notably, there was significant decline in thin (below $5^{\text {th }}$ percentile) children from $67.5 \%$ to $60.8 \%$ and there is increase in normal children with BMI for age $\left(5^{\text {th }}-85^{\text {th }}\right.$ percentile) from $32.2 \%$ to $38.5 \%$. Conclusions The need based participatory Health Promoting School initiative for vulnerable Ashram school children could improve their health status.

\section{P1-420 FIBRE INTAKE AND EVOLUTION OF BODY MASS INDEX: FROM PREPREGNANCY TO POSTPARTUM}

doi:10.1136/jech.2011.142976g.10

M Drehmer, ${ }^{*}$ S Camey, M A Nunes, B Duncan, M Lacerda, M I Schmidt. Universidade Federal do Rio Grande do Sul, Programa de Pós-Graduação em Epidemiologia, Porto Alegre, Rio Grande do Sul, Brazil

Background Postpartum weight retention is important risk factor for obesity in reproductive age women. The role of fibre intake still needs clarification, being among those dietetic factors that may be associated with a positive evolution of postpartum weight variation. Objectives To evaluate the effect of fibre intake on the evolution of maternal body mass index (BMI) from pregnancy to postpartum, and to identify dietary patterns associated with fibre intake.

Methods A cohort of 370 pregnant women was followed until the sixth month of postpartum. Food intake was obtained using foodfrequency questionnaire. Focused principal component analysis was used centered on postpartum weight retention and on total dietary fibre intake. Obesity risk was a variable defined to indicate unfavourable evolution of BMI in postpartum. Poisson regression was used to estimate the association between fibre intake and obesity risk.

Results Participants retained a median of $4.4 \mathrm{~kg}$ (IR 0.6; 7.9), and obesity risk was present in $55.1 \%(n=189)$ of the sample. Individual food items did not have an important effect on weight retention. The highest contribution of fibre intake came from the consumption of beans. Consumption of bread and rice indicated a common Brazilian food pattern along with beans. In the multivariable model, inadequate fibre intake increased $24 \%$ (95\% CI 1.05 to 1.47$)$ the obesity risk, after adjusting for maternal age, prepregnancy BMI and total gestational weight gain.

Conclusion Maternal BMI showed an increasing trend from prepregnancy to postpartum. Adequate fibre intake may reduce obesity risk in the period following childbirth.

\section{P1-421 DETERMINANTS OF SATISFACTION WITH HEALTHCARE: A POPULATION-BASED STUDY FROM IRAN}

doi:10.1136/jech.2011.142976g.11

F Farzadi, A Montazeri, ${ }^{*}$ J Sadighi, S Omidvari, F Maftoon, A Aeenparast, K Jahangiri, M Vahdaninia. Iranian Institute for Health Sciences Research, ACECR, Tehran, Iran

Introduction Satisfaction with healthcare is an important indicator of effective healthcare delivery. It could contribute to both policy and practice.

Methods This was a nationwide cross sectional study. A random sample of individuals aged between 18 and 65 were entered into study. Respondents were asked to rate their overall satisfaction with healthcare on a 5-point scale. The record of demographic and socioeconomic data included age, gender, education, marital status, employment, income, and chronic diseases. Logistic regression 